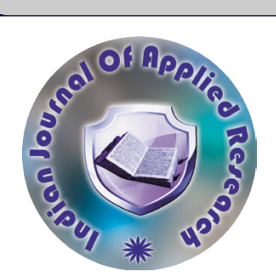

Gastroenterology

\title{
WOMEN IN THE AGE GROUP OF 20 TO 50 YEARS ARE LESS PRONE TO DEVELOP NAFLD IN KERALA, SOUTH INDIA: A POPULATION BASED STUDY
}

\section{Shenoy K T*}

Department of Gastroenterology, Sree Gokulam Medical College and Research Foundation, Trivandrum, India. *Corresponding Author

\section{Leena K B}

\section{Sheela Shenoy $\mathrm{T}$}

Population Health and Research Institute, Holistic Health and Research Institute, Trivandrum.
Department of Obstetrics and Gynaecology, Cosmopolitan Hospitals, Trivandrum, India.

ABSTRACT Aim: To investigate frequency, gender-specific differences and impact of polymorphisms in Non alcoholic Fatty Liver Disease (NAFLD) among the population of Kerala State, South India with a high incidence of type 2 Diabetes Mellitus

(Type 2 DM).

Methods: In a Community based study, data were collected on anthropometry, blood pressure, morbidity patterns and Ultrasound was carried out in 484 subjects. 121 subjects were excluded due to other findings on ultrasonography, hepatitis B and C. 363 subjects, 126 with NAFLD (cases) and 237 with no NAFLD (controls) were evaluated. Blood samples collected after 12 hours fasting were analysed for blood glucose, Liver Function Tests, Lipid profile and Genetic studies for MTP polymorphisms.

Results: A low prevalence of NAFLD was noted in women below the age of 50 years $(\mathrm{P}<0.05)$. Prevalence of Type 2 DM was $14 \%$ and more common in men $(\mathrm{P}=0.002)$. Mean BMI was 25.5 for the NAFLD group and 23.2 for controls

$(\mathrm{p}<0.001)$. Women with NAFLD had higher BMI $(\mathrm{P}=0.003)$, systolic blood pressure (SBP) $(\mathrm{P}=0.030), \mathrm{LDL}(\mathrm{P}=0.001), \mathrm{HDL}(\mathrm{P}=0.001)$ and alkaline phosphatase $(\mathrm{P}<0.001)$ than men with NAFLD. Women with NAFLD had increased total cholesterol, higher AST/ALT ratio, $(\mathrm{P}<0.001)$ and diastolic $\mathrm{BP}(\mathrm{P}=0.061)$ compared to women controls.

Microsomal triglyceride transfer protein (MTP) T-substitution at -493 was significantly more common in NAFLD than controls $(\mathrm{P}=0.003)$. High prevalence was noted among females as carriers $(\mathrm{P}=0.002)$. More than $80 \%$ of the T-allele carriers were females in the $20-50$ years of age group, compared to $25 \%$ among males.

Conclusion: Women under 50 years of age had less NAFLD but more often had type 2 DM, metabolic syndrome, high BMI and the MTP -493 mutation. The specific age cut-off, for differences, indicates that estrogens may play an important role.

KEYWORDS : Non alcoholic fatty liver disease, diabetes, gender, Microsomal triglyceride transfer protein, India.

\section{INTRODUCTION}

Non alcoholic fatty liver disease (NAFLD), with a prevalence of approximately $25 \%$, is the most common chronic liver disease in the world today ${ }^{1}$. This condition is primarily associated with obesity ${ }^{2}$ noninsulin-dependent diabetes mellitus ${ }^{3}$, hyperlipidemia ${ }^{4,5}$ and insulin resistance, ${ }^{6}$ i.e. the major characteristics of the metabolic syndrome, and is considered as a part of this syndrome

Fatty liver, or simple steatosis, can progress to non alcoholic steatohepatitis or $\mathrm{NASH}^{8,9}$. Further progression involves increasing cell damage and hepatic fibrosis, cirrhosis and, possibly, hepatocellular carcinoma, ${ }^{9,3}$. Currently, there is no effective drug to reduce the fibrosis, although suggestions regarding treatment with vitamin $\mathrm{E}^{10}$, metadoxine ${ }^{11}$, saroglitazone ${ }^{12}$ and obitocholic acid ${ }^{13}$ are emerging.

The fatty infiltrated liver is insulin resistant ${ }^{14}$ and it has been proposed that there exists a relationship between the hepatic fat content and the degree of insulin resistance. Furthermore, fatty livers overproduce glucose ${ }^{14}$ and VLDL ${ }^{, 15}$ and NAFLD has recently been reported to be an important emerging risk factor for cardiovascular disease ${ }^{16,17}$. In Kerala, a small state in southern India, NAFLD, insulin resistance, metabolic syndrome and incidence of Type $2 \mathrm{DM}$ are high ${ }^{18}$.

Several studies have reported genetic variations explaining NAFLD incidence ${ }^{19-22}$, progression to NASH ${ }^{20,23}$ and impact on alcoholic fatty liver disease ${ }^{24}$. In order to show if metabolic syndrome was the major factor or if genetic factors are involved, we chose to study polymorphisms in lipid regulating genes. There are contradictory reports on the importance of the microsomal triglyceride transfer protein (MTP) gene and especially the -493 polymorphism and its effect on cholesterol and triglyceride levels ${ }^{25-28}$.

The MTP T-allele is described as a risk factor for severe hepatic steatosis grade in combination with hepatitis $\mathrm{C}$ infection ${ }^{29,30} \mathrm{In}$ order to study the impact of obesity and Type 2 DM, we evaluated the prevalence and gender difference of NAFLD in a population based study. In addition, we wanted to demonstrate whether polymorphisms in lipid regulating genes could be a modifying factor.

\section{METHODS}

\section{Subjects:}

This study was performed in the Trivandrum district of southern Indian state of Kerala. This state has the highest rate of literacy in India contains groups of people with a variety of diets and ethnic and religious backgrounds in addition to exhibiting health indices more favourable than those in other regions of India. It also keeps good records and demographic documentation.

Our subjects were selected using random sampling of 5 of the 81 wards in accordance with a model described previously from the city of Trivandrum. ${ }^{31,32}$ Each ward was subdivided into clusters of seven houses . 3-5 such clusters from each ward were then selected randomly for inclusion. We excluded subjects using medication such as phenytoin sodium, valproic acid, Isoniazid or sulfonamides; a history of alcohol or substance abuse (see also below). Written informed consent was received from each subject prior to enrolment in this investigation.

484 subjects (256 men and 228 women in the age range 20-70), selected from the population of approximately 200000 , answered questions regarding their medical history, nutritional profile, smoking, intake of alcohol and physical activity. Anthropometry ,blood pressures and ultrasonography of their livers were performed. Blood samples were taken after fasting. All subjects were examined for hepatitis $\mathrm{B}$ and $\mathrm{C}$ virus (HBV and $\mathrm{HCV}$ ) by HBs antigen ELISA and anti HCV ELISA, aspartate aminotransferase (AST), alanine aminotransferase (ALT), alkaline phosphatase, serum bilirubin, immunoglobulins, albumin, ferritin, lipid profile, blood glucose and fasting levels of serum insulin, total level of triglycerides, high-, lowand very low- density lipoprotein (HDL, LDL, VLDL) and total cholesterol.

Ultrasound was performed with a Logic 400 Ultrasound Scanner (Wipro G E) with a $3.5 \mathrm{MHz}$ probe. After scanning, all subjects were evaluated according to the four level scale for ultrasound grading of fatty liver ${ }^{33}$ Level $0=$ a normal hepatic echo pattern, Level $1=$ a slight increase in the echo pattern but normal appearance of vessels and the diaphragm. Level 2 = a moderate elevation in echogenicity along with 
reduced visualization of portal veins and the diaphragm and Level $3=\mathrm{a}$ pronounced enhancement in the hepatic echo pattern with poor visualization of intrahepatic vessels and the posterior right lobe of the liver. 32 patients were excluded from the study (one upon finding a cystic region in the pancreas, eleven due to kidney cysts and three because of cystic areas in the liver, one because of calculi in the liver, two from calculi in in the kidney and nine from calculi in the gall bladder. One patient was excluded due to signs of liver cirrhosis, one because of a gall bladder polyp and three who had coarse parenchymal echotexture of the liver).

Cases of NAFLD $(n=126)$ were identified on the basis of the ultrasonographic findings in combination with their daily intake of alcohol ( $<20 \mathrm{~g}$ for women, $<30 \mathrm{~g}$ for men). The individuals exhibiting normal liver ultrasonography and no other evidences of liver disease served as controls $(\mathrm{n}=237)$.

\section{MTP-493 genotyping}

DNA was purified from 180 persons ( 89 with NAFLD and 91 controls) from whole blood and buffy coat samples using the QIAamp ${ }^{\circledR}$ Mini Kit from Qiagen Ltd. (West Sussex UK). Kit was used according to manufacturer's instructions.

Polymerase Chain Reaction-Restriction Fragment Length Polymorphism (PCR-RFLP) using specified primers (shown below) were used for evaluating each SNP. Generally, we used 30-35 cycles of PCR with $200 \mu \mathrm{M}$ dNTP, $0.4 \mu \mathrm{M}$ of primer, $0.025 \mathrm{U} / \mathrm{L}$ of Taq Polymerase and $1.5 \mathrm{mM} \mathrm{MgCl}_{2}$ concentration. PCR was followed by restriction enzyme analysis to verify the presence or absence of cleavage-site due to polymorphism.

The MTP $-493 \mathrm{G} / \mathrm{T}$ polymorphism was evaluated as previously described ${ }^{29}$. Briefly, we used nested PCR with first round being; 35 cycles at $94^{\circ} \mathrm{C}$ for 30 seconds, $55^{\circ} \mathrm{C}$ for 60 seconds, and $72^{\circ} \mathrm{C}$ for 3 minutes. We also increased the $\mathrm{MgCl}_{2}$ concentration to $2.0 \mathrm{mM}$ to enhance the specificity of the amplification. Primers were: OuterFrw5': CCCTCTTAAT CTCTTTCCTAGAA. Outer-Rev5': AAGAATCATATTGACCAG CAATC. The second round of PCR the number of cycles was changed to 35 at $94^{\circ} \mathrm{C}$ for 30 seconds, $57^{\circ} \mathrm{C}$ for 60 seconds, and $72^{\circ} \mathrm{C}$ for 2 minutes. The $-493 \mathrm{G} / \mathrm{T}$ SNP does not cause a restriction site with any common restriction enzyme. However, a mutation in the 5' primer used for PCR of a gene product including the 493 site gave rise to an $H p h 1$ cutting site for the $-493 \mathrm{G}$ allele. The PCR (Inner Frw5'-GGA TTT AAA TTT AAA CTG TTA ATT CAT ATC AC and Inner Rev5'-AGT TTC ACA CAT AAG GAC AAT CAT CTA) gave rise to a 109 -bp fragment, and the gene product was cleaved by $H p h 1$. Analyzing the fragments on a 2,5\% agarose gel (Agarose-1000) the $-493 \mathrm{~T}$ allele gave rise to a full-length fragment (109 bp), whereas the $-493 \mathrm{G}$ allele gave rise to two fragments of 89 and $20 \mathrm{bp}$.

\section{Definition Of Metabolic Syndrome}

Metabolic syndrome was defined as per the International Diabetes Federation (IDF) $2005^{34}$. This definition stipulates the mandatory presence of central obesity (with a waist circumference of $>80 \mathrm{~cm}$ for women and $>90$ for men in Asian Indians) in combination with at least two of the following criteria: total serum level of triglycerides $>1.7$ $\mathrm{mmol} / \mathrm{L}(150 \mathrm{mg} / \mathrm{dl}) ; \mathrm{HDL}<1.3 \mathrm{or}<1.0 \mathrm{mmol} / \mathrm{L}(<51$ or $<39 \mathrm{mg} / \mathrm{dl})$ for women, and men respectively; blood pressure $>130 / 85$ or on-going anti-hypertensive treatment; a fasting level of plasma glucose $>5.6$ $\mathrm{mmol} / \mathrm{L}(100.8 \mathrm{mg} / \mathrm{dl})$; and/or Type $2 \mathrm{DM}$.

\section{Insulin resistance according to HOMA2}

Insulin resistance and insulin sensitivity were calculated in accordance with the updated version of the homeostasis model assessment (HOMA2) utilizing the HOMA calculator (version 2.2; Diabetes Trials Unit, University of Oxford) (see http://www.dtu.ox.ac.uk/index.php? maindoc $=$ /homa/index.php)

\section{Statistical Analysis}

All of the data sets were first evaluated for deviation from a normal distribution. Thereafter, values not exhibiting normal distribution were evaluated for statistical significance employing the Kruskal-Wallis $\mathrm{H}$ and non-parametric median tests; normally distributed values were tested using the independent t-test, ANOVA (coupled to post-hoc Scheffe), multivariate linear regression or multinominal logarithmic regression. All computations and calculations were performed with the SPPS v25 for windows (Statistical Package for the Social Sciences, SPSS Inc, U.S.A).

\section{Ethical Permission}

This study was approved by the Human Ethical Committee of the Medical College of Trivandrum and Sree Gokulam Medical College and Research Foundation. Written informed consent was received from each subject prior to enrolment in this investigation.

\section{RESULTS}

We had 126 subjects with fatty liver (67 men and 59 women) and 237 controls (103 men, 134 women). Age of the cases and controls were (mean $\pm \mathrm{sd}$ ) $48.5 \pm 11.1$ and $48.4 \pm 12.2$ respectively for the cases and controls $(\mathrm{p}=0.971)$. In the NAFLD group, the average age was 48.5 years ( 48.5 for men and 48.4 for women) and 48.4 years ( 51.9 for men and 45.8 for women) for the controls. Both groups were similar with respect to their distribution of age and sex (Table 1$)$.

Anthropometry, biochemical and morbidity pattern

This is represented in Table1. The mean BMI for the subjects with NAFLD was $25.5 \mathrm{~kg} / \mathrm{M}^{2}$ (24.4 for men and 26.8 for women) and 23.2 $\mathrm{kg} / \mathrm{M}^{2}$ (22.2 for men and 24.0 for women) for the control group. The subjects with NAFLD had larger waist and hip measurements, a higher HOMA2 IR in comparison to the controls. The AST/ALT ratio was lower than in controls.

\section{Type 2 DMand the metabolic syndrome.}

There were no differences between NAFLD and controls, $14 \%(n=18)$ and $14 \%(n=34)$ respectively $(P=0.569)$ nor for NAFLD to diabetes among women $(\mathrm{P}=0.431)$ or men $(\mathrm{P}=0.841)$. Sub-group results are illustrated in figure 1 but groups were deemed too small to merit statistical analysis.

Table1. Gender-specific Differences Within And Between The NAFLD And Control Groups.

\begin{tabular}{|c|c|c|c|c|c|c|c|c|}
\hline Factor & $\begin{array}{l}\text { Men without } \\
\text { NAFLD } \\
(\mathrm{n}=103)\end{array}$ & $\begin{array}{l}\text { Men with } \\
\text { NAFLD } \\
\text { (n=67) }\end{array}$ & \begin{tabular}{|l|}
$P$-value \\
(Men without \\
NAFLD vs Men \\
with NAFLD)
\end{tabular} & $\begin{array}{l}\text { Women } \\
\text { without } \\
\text { NAFLD } \\
(\mathrm{n}=134)\end{array}$ & $\begin{array}{l}\text { Women } \\
\text { with } \\
\text { NAFLD } \\
(n=59)\end{array}$ & \begin{tabular}{|l}
$P$-value \\
(Women without \\
NAFLD vs Women \\
with NAFLD)
\end{tabular} & \begin{tabular}{|l|}
-value \\
(Men vs women \\
Without \\
NAFLD)
\end{tabular} & $\begin{array}{l}P \text {-value } \\
\text { (Men vs } \\
\text { women with } \\
\text { NAFLD) }\end{array}$ \\
\hline Age (years) & $51.9 \pm 11.1$ & $48.5 \pm 11.0$ & 0.327 & $45.8 \pm 12.3$ & $48.4 \pm 11.4$ & 0.535 & 0.001 & 1.000 \\
\hline BMI $\left(\mathrm{kg} / \mathrm{m}^{2}\right)$ & $22.2 \pm 3.1$ & $24.4 \pm 3.3$ & 0.002 & $24.0 \pm 3.8$ & $26.8 \pm 4.5$ & $<0.001 \dagger$ & $0.006 \%$ & $0.003 \%$ \\
\hline SYS (mm Hg) & $128 \pm 19$ & $128 \pm 13$ & 1.000 & $125 \pm 15$ & $134 \pm 18$ & 0.004 & 0.475 & 0.264 \\
\hline DIA (mm Hg) & $82 \pm 10$ & $83 \pm 8$ & 0.841 & $81 \pm 8$ & $85 \pm 11$ & 0.061 & 0.940 & 0.742 \\
\hline HOMA2 IR & $0.74 \pm 0.48$ & $1.07 \pm 0.73$ & $0.002 \%$ & $0.81 \pm 0.63$ & $1.14 \pm 0.75$ & $<0.001 \dagger$ & $0.588 t$ & $0.549 \%$ \\
\hline Diabetes & 21 & 12 & 0.690 & \begin{tabular}{|l|l|}
13 \\
\end{tabular} & 6 & 0.874 & 0.021 & 0.245 \\
\hline Metabolic syndrome & 26 & 23 & 0.622 & 39 & 28 & 0.125 & 0.700 & 0.224 \\
\hline AST (IU/L) & $23.7 \pm 12.8$ & $30.0 \pm 16.4$ & $0.013 \%$ & $18.0 \pm 7.8$ & $30.9 \pm 15.3$ & $<0.001 \%$ & $<0.001 \dagger$ & $0.467 \%$ \\
\hline ALT (IU/L) & $17.6 \pm 14.4$ & $28.9 \pm 22.6$ & $0.001 \%$ & $14.3 \pm 10.8$ & $31.0 \pm 17.2$ & $<0.001 \%$ & $0.110 \%$ & $0.140 \%$ \\
\hline AST/ALT & $1.92 \pm 1.48$ & $1.42 \pm 0.78$ & $0.221 t$ & $1.62 \pm 1.22$ & $1.07 \pm 0.33$ & $<0.001 \dagger$ & $0.102 \%$ & $0.123 \%$ \\
\hline Ferritin $(\mathrm{pmol} / \mathrm{L})$ & $99 \pm 98$ & $146 \pm 115$ & $0.005 t$ & \begin{tabular}{|l|}
$41 \pm 39$ \\
\end{tabular} & $73 \pm 42$ & $<0.001 \uparrow$ & $<0.001 \dagger$ & $<0.001$ \\
\hline $\mathrm{TG}(\mathrm{mg} / \mathrm{dL})$ & $113 \pm 70$ & $159 \pm 74$ & $<0.001 t$ & $103 \pm 65$ & $145 \pm 57$ & $<0.001 \dagger$ & $0.141 \%$ & $0.437 t$ \\
\hline HDL (mg/dL) & $38 \pm 11$ & $42 \pm 12$ & 0.290 & $41 \pm 13$ & $54 \pm 14$ & $<0.001 \dagger$ & $0.085 \dagger$ & $0.001 \%$ \\
\hline LDL (mg/dL) & $127 \pm 41$ & $133 \pm 50$ & 0.909 & $131 \pm 42$ & $167 \pm 52$ & $<0.001+$ & $0.968 t$ & $0.001+$ \\
\hline VLDL (mg/dL) & $23 \pm 14$ & $34 \pm 21$ & $<0.001 \dagger$ & $21 \pm 14$ & $29 \pm 11$ & $<0.001 \%$ & $0.132 \%$ & $0.425 \%$ \\
\hline Total Cholest. $(\mathrm{mg} / \mathrm{dL})$ & $187 \pm 50$ & $209 \pm 59$ & 0.100 & $193 \pm 52$ & $249 \pm 58$ & $<0.001 \%$ & $0.980 \dagger$ & $<0.001 \dagger$ \\
\hline Alb. & $4.1 \pm 0.70$ & $4.2 \pm 0.70$ & $0.462 \dagger$ & $3.89 \pm 0.75$ & $4.33 \pm 0.61$ & $<0.001 \dagger$ & $0.0 .14 \dagger$ & $0.392 \dagger$ \\
\hline
\end{tabular}


Statistically significant differences were examined for as described in the Materials and Methods + Values not demonstrating a normal distribution and therefore analyzed using the Kruskal-Wallis H non-parametric test. Abbreviations: SYS=Systolic blood pressure, DIA=Diastolic blood pressure, $H D L=$ high-density lipoprotein, $L D L=$ low-density lipoprotein and $V L D L=v e r y$ low-density lipoprotein. TG $=$ Triglycerides. $A S T=$ Aspartate aminotransferase $. A L T=$ Alanine aminotransferase .

Type $2 \mathrm{DM}$ was more common in men $(\mathrm{P}=0.002)$. (OR; and $95 \%$ confidence interval c.i) 2.31 (1.33-4.01). One hundred and sixteen (49 men and 67 women) had metabolic syndrome. Among those with NAFLD, 51 subjects had metabolic syndrome ( 23 men and 28 women, $(40.0 \%))$, in comparison to 65 (26 men and 39 women $(27 \%))$ of the controls $(\mathrm{P}=0.173)$. There was no significant correlation of NAFLD to metabolic syndrome among either women $(\mathrm{P}=0.125)$ or men $(\mathrm{P}=$ $0.622)$. However, the HOMA2 IR values for the NAFLD group were 1.10 (1.07 for men and 1.14 for women), compared to 0.78 ( 0.74 for men and 0.81 for women) for the controls $(\mathrm{P}<0.001)$.

\section{Gender-specific findings}

Calculated from the 180 genotyped persons, NAFLD was significantly more common among men than women up to the age of $50,(\mathrm{P}=0.036)$ but not after, as shown in figure 1. However, including non-genotyped persons, male prevalence is still higher but not significantly so. Based on 363 persons, there was also a tendency towards increased fatty infiltration, as determined by ultrasound, for male diabetics $(\mathrm{P}=0.092)$ but not female $(\mathrm{P}=0.524)$. Among the cases with NAFLD women exhibited significantly higher levels of LDL and HDL cholesterol than men. No such gender difference was seen among the healthy controls. Metabolic syndrome was higher in NAFLD women younger than 50 years (table 2). Similarly, high BMI, high blood pressure and high serum lipids were seen higher in this group than men with NAFLD (not shown in table) $(\mathrm{P}<0.001)$. After the age of 50, there are no significant differences between the genders. Certain gender-specific differences, e.g a higher serum level of ferritin, were observed for both NAFLD cases and controls (Table 2).
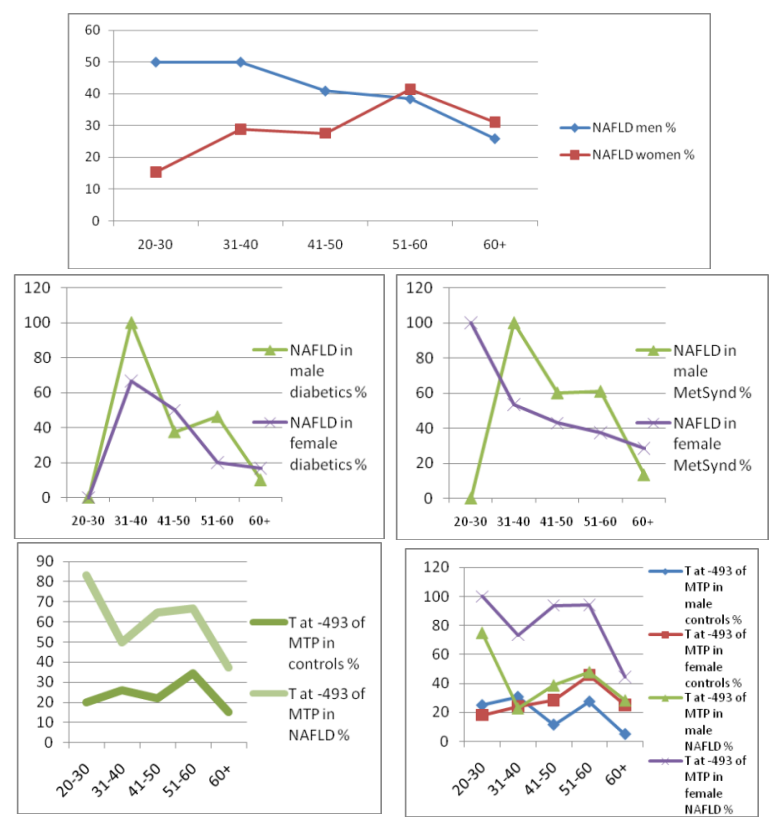

Fig1 NAFLD by gender, metabolic syndrome, MTP -493 G/T polymorphism

Table 2 Diabetes mellitus, Homa2 IR, metabolic syndrome and T at $\mathbf{- 4 9 3}$ of $\mathrm{MTP}$ by age and gender in cases and controls

\begin{tabular}{|c|c|c|c|c|c|c|c|c|c|c|c|c|}
\hline Variable & \multicolumn{6}{|c|}{ Non NAFLD Controls } & \multicolumn{6}{|c|}{ NAFLD Cases } \\
\hline $\begin{array}{l}\text { Mean } \pm \text { sd } \\
\text { age* (range) }\end{array}$ & \multicolumn{6}{|c|}{$48.4 \pm 12.2((24-66))$} & \multicolumn{6}{|c|}{$48.5 \pm 11.1(24-68)$} \\
\hline Age group & \multicolumn{3}{|c|}{$20-50$} & \multicolumn{3}{|c|}{$50+$} & \multicolumn{3}{|c|}{$20-50$} & \multicolumn{3}{|c|}{$50+$} \\
\hline Gender & $\mathrm{M}$ & $\mathrm{F}$ & Tota & $\mathrm{M}$ & $\mathrm{F}$ & Total & $\mathrm{M}$ & $\mathrm{F}$ & Total & $\mathrm{M}$ & $\mathrm{F}$ & Total \\
\hline Number & 43 & 90 & 133 & 60 & 44 & 104 & 35 & 33 & 68 & 32 & 26 & 58 \\
\hline $\begin{array}{l}\text { Diabetes } \\
\text { mellitus }\end{array}$ & 5 & 3 & 8 & 16 & 10 & 26 & 5 & 4 & 9 & 7 & 2 & 9 \\
\hline HOMA2 IR & \multicolumn{3}{|c|}{$0.74 \pm 0.48$} & \multicolumn{3}{|c|}{$0.77 \pm 0.67$} & \multicolumn{3}{|c|}{$1.08 \pm 0.64$} & \multicolumn{3}{|c|}{$1.11 \pm 0.73$} \\
\hline $\begin{array}{l}\text { Metabolic } \\
\text { syndrome** }\end{array}$ & 4 & 19 & 13 & 22 & 20 & 42 & 7 & 18 & 25 & 16 & 10 & 25 \\
\hline $\begin{array}{l}\text { T at }-493 \text { of } \\
\text { MTP }\end{array}$ & 8 & 23 & 31 & 11 & 11 & 22 & 13 & 28 & 41 & 14 & 20 & 34 \\
\hline
\end{tabular}

* P-value age (Non-NAFLD controls vs NAFLD) 0.971

** Metabolic syndrome was significantly more common in women up to the age of $50(\mathrm{P}=0.029)$.

\section{MTP-493 G/T polymorphism}

The allele frequencies of the MTP-493 G/T SNP followed the HardyWeinberg equilibrium and showed NAFLD: G: 0.42, T: 0.58; Controls: G: 0.59 and $T: 0.41$.

The T-substitution at -493 was significantly associated with an increased risk of NAFLD $(\mathrm{P}=0.003)$ (figure 1$)$. The odds ratio (OR; and $95 \%$ confidence interval c.i) for the T-substitution in the NAFLD cohort (as calculated for the T-dominant model) was 2.91 (1.42-5.94). $\mathrm{T} / \mathrm{T}$ at position -493 was also associated with increased total cholesterol $(\mathrm{P}=0.033)$, LDL $(\mathrm{P}=0.038)$ and HDL $(\mathrm{P}=0.003)$ but not VLDL compared to $\mathrm{G} / \mathrm{G}$. Triglyceride $(\mathrm{P}=0.044)$ and VLDL $(\mathrm{P}=0.026)$ values were significantly lower for T homozygotes, compared to $G / G$ and $\mathrm{G} / \mathrm{T}$ in people with NAFLD, as were Alkaline Phosphatase values $(\mathrm{P}=0.032)$. As shown in figure $1, \mathrm{~T}$ at position -493 was also significantly overrepresented in women $(\mathrm{P}=0.002)$, with $45.1 \%$ of the women being carriers compared to $27.6 \%$ among the men. In some age-groups almost $100 \%$ of the women with NAFLD were carriers.

\section{DISCUSSION}

In this study, there is a high incidence of NAFLD, with a genderspecific pattern, in a region with very high incidence of type $2 \mathrm{DM}$ in a population. Insulin resistance but not type $2 \mathrm{DM}$ is correlated to NAFLD and a weak tendency that metabolic syndrome and NAFLD may be correlated. Furthermore, we also find genetic differences between the NAFLD- and the control group. Major differences were found between men and women below the age of 50 . To our knowledge, this is the first report to emphasize the significant differences between men and women with NAFLD in an epidemiologically selected population.

We used the sampling technique as described in earlier studies ${ }^{31,32}$. It provides an unbiased sample of subjects from areas representative of the region as a whole. We used ultrasound in order to detect NAFLD which is an accepted method, although patients with less than 5-10\% fat in the liver are not identified ${ }^{33}$. It is unehical to perform a liver biopsy on persons not seeking health care. 35\% had NAFLD which is higher than reported from Europe and the United States ${ }^{35-37}$ and the high incidence of type 2 Diabetes Mellitus may be an important factor. A high prevalence of NAFLD has been reported before in this region ${ }^{38}$ and previous author have speculated that the high frequency of metabolic syndrome and DM type 2 is of importance. In our study we also found a high prevalence of MTP polymorphisms which indicates that genetic factors are important in combination with dietary factors.

Interestingly, although the total group with NAFLD did have higher BMI values than the healthy controls these values were still not very high and indicative of overweight rather than obesity. Only women with NAFLD had a mean BMI over 25. Moreover, we found that approximately $20 \%$ of the non-diabetic subjects with NAFLD were of normal weight, but nonetheless met the IDF criteria for presence of the metabolic syndrome as have been reported to similar extent before ${ }^{8}$. In addition we found no significant correlation between the metabolic syndrome and NAFLD except in specific age-groups and although our study population demonstrated a high incidence $(>14 \%)$ of Type 2 DM, the presence of NAFLD did not significantly correlate with that of diabetes. This is not unheard of and it has been shown that although NAFLD is usually associated with obesity and diabetes the latter conditions are not in any way essential for the development of NAFLD ${ }^{16}$.

The fact that patients with and without NAFLD had the same prevalence of Diabetes is interesting and Diabetes may be something that increase the risk for NAFLD but other factors, which we have described, are necessary in order to increase the amount of triglycerides in the liver and cause NAFLD. Much more research, maybe on a genetic level, is needed to respond to this question. However, there was a correlation between NAFLD and HOMA2 insulin resistance. According to recent investigations, this correlation may indicate impaired insulin clearance and secretion, rather than altered insulin sensitivity ${ }^{1.5}$. 
Blood tests showed that serum levels of Alkaline phosphates were higher in NAFLD patients, something which has been shown for NASH patients before ${ }^{5}$. However that AST/ALT ratio were lower in NAFLD patients than controls which is an unexpected finding since the reversed would be expected, also previously shown in NASH patients. HDL levels were higher in women, which is known since before and is caused by estrogen. It is however not clear why HDL was higher in the female NAFLD group compared to female controls and we have no explanation for this. This was not found in men.

We found that $\mathrm{T}$ at position -493 is significantly associated with NAFLD. This is in agreement with recent reports describing correlation between the T-allele and advanced hepatic steatosis in subjects with hepatitis $\mathrm{C}$ viral infection ${ }^{29,30}$, Interestingly, the $\mathrm{T}$ allele frequency was much higher in this cohort compared to the Framingham offspring study which analyzed 2510 , mostly Caucasian, subjects ${ }^{27}$. Furthermore, we found that women are overrepresented by almost a 2 to 1 ratio as carriers of the T-dominance. Some investigators have reported NAFLD prevalence to vary between men and women ${ }^{35}$ ${ }^{37}$ and other interesting genetic variations possibly explaining NAFLD incidence ${ }^{19-22}$, progression to $\mathrm{NASH}^{20,23}$ and impact on alcoholic fatty liver disease ${ }^{24}$ have also been described. We found no significant difference when analyzing the total cohort. NAFLD was more common among males, in our cohort, in younger ages but the difference disappears for older subjects. A reason for this might be estrogen, suggested as a protective factor in liver disease including NAFLD/NASH/ASH in human subjects as well as animal models ${ }^{40-43}$.

Thus, after menopause, the protective effect is diminished and, women over the age of 50 have equal (or even more based on the genotyped persons) NAFLD than men of the same age. A fact that may be explained by the overrepresentation of MTP -493 T-substitution in women. We suggest that men in this cohort develop NAFLD partially due to "classical" reasons like type 2 diabetes, with an increased risk stemming from the MTP polymorphism, and that women who are overrepresented for the T-substitution, would have increased prevalence if not protected by estrogen. Thus, we suggest that these findings are indicative of gender-specific profiles for NAFLD.

\section{REFERENCES}

1. Younossi ZM, Koenig AB, Abdelatif D, et al. Global epidemiology of nonalcoholic fatty liver disease-Meta-analytic assessment of prevalence, incidence, and outcomes.
live liver disease-Meta-analytic
Hepatology 2016; $64: 73-84$.

2. Shenoy K T, Leena K B,Shenoy S T. Prevalence and risk factors for non-alcoholic fatty liver in a transition society with high incidence of diabetes mellitus. In The $15^{\text {th }}$ Annual Conference of the INASAL. Vellore, 2007

3. de Alwis NM, Day CP. Non-alcoholic fatty liver disease: the mist gradually clears. Journal of Hepatology. 2008 ;48 Suppl 1:S104-12. DOI: 10.1016/j.jhep.2008.01.009.

4. Ratziu V, Giral P, Charlotte F, Bruckert E, Thibault V, Theodorou I, et al. Liver fibrosis in overweight patients. Gastroenterology. 2000;118(6):1117-1123. doi:10.1016/s00165085(00)70364-7

5. Bacon BR, Farahvash MJ, Janney CG, Neuschwander-Tetri BA. Nonalcoholic Bacon BR, Farahvash MJ, Janney CG, Neuschwander-Tetri BA. Nonalcoholic
steatohepatitis: an expanded clinical entity. Gastroenterology. 1994;107(4):1103-1109. steatohepatitis: an expanded clinical
doi: 10.1016/0016-5085(94)90235-6

6. Marchesini G, Brizi M, Bianchi G, Tomassetti S, Bugianesi E, Lenzi M, et al. Nonalcoholic fatty liver disease: a feature of the metabolic syndrome. Diabetes. 2001;50(8):1844-1850. doi:10.2337/diabetes.50.8.1844

7. Pagano G, Pacini G, Musso G, Gambino R, Mecca F, Depetris N, et al. Nonalcoholic steatohepatitis, insulin resistance, and metabolic syndrome: Further evidence for an etiologic association. Hepatology 2002;35:367-72

8. Marchesini G, Bugianesi E, Forlani G, et al. Nonalcoholic fatty liver, steatohepatitis, and the metabolic syndrome. Hepatology. 2003;37(4):917-923. doi:10. 1053/jhep. 2003.50161

Söderberg C, Stål P, Askling J, Glaumann H, Lindberg G, Marmur J, et al. Decreased survival of subjects with elevated liver function tests during a 28 -year follow-up. Hepatology. 2010;51(2):595-602. doi:10.1002/hep.23314

10. Sanyal AJ, Chalasani N, Kowdley KV, McCullough A, Diehl AM, Bass NM, et al Pioglitazone, vitamin E, or placebo for nonalcoholic steatohepatitis. N Engl J Med. 2010;362(18):1675-1685. doi:10.1056/NEJMoa0907929.

11. Shenoy KT, Balakumaran LK, Mathew P, Prasad M, Prabhakar B, Sood A, Singh SP, Rao NP, Zargar SA, Bignamini AA. Metadoxine Versus Placebo for the Treatment of Non-alcoholic Steatohepatitis: A Randomized Controlled Trial. Journal of Clinical and Experimental Hepatology. 2014 Jun;4(2):94-100. DOI: 10.1016/j.jceh.2014.03.041.

12. Gawrieh S, Noureddin M, Loo N M, Mohseni R, Awasty V R, Cusi K. et al . A phase 2, prospective, multicentre, double blind randomized study of Saroglitazar Magnesium 1 $\mathrm{mg}, 2 \mathrm{mg}$ or $4 \mathrm{mg}$ versus placebo in patients with non alcoholic fatty liver disease and/or non alcoholic steatohepatitis ( EVIDENCES IV). Hepatology 2019, 70, NUMBER 6 (SUPPL); Abstract \#LO10 1484A-1485A

13. Younossi ZM, Ratziu V, Loomba R, et al. Obeticholic acid for the treatment of nonalcoholic steatohepatitis: interim analysis from a multicentre, randomised, placebocontrolled phase 3 trial. Lancet. 2019;394(10215):2184-2196. doi:10.1016/S01406736(19)33041-7

14. Seppälä-Lindroos A, Vehkavaara S, Häkkinen AM, et al. Fat accumulation in the liver is associated with defects in insulin suppression of glucose production and serum free fatty acids independent of obesity in normal men. J Clin Endocrinol Metab. 2002;87(7):30233028. doi: 10.1210 /jcem.87.7.8638

15. Adiels M, Taskinen MR, Packard C, Caslake MJ, Soro-Paavonen A, Westerbacka J, et al. Overproduction of large VLDL particles is driven by increased liver fat content in man. Diabetologia. 2006;49(4):755-765. doi:10.1007/s00125-005-0125-z.

16. Musso G, Gambino R, Bo S, Uberti B, Biroli G, Pagano G, et al. Should nonalcoholic fatty liver disease be included in the definition of metabolic syndrome? A cross-sectional comparison with Adult Treatment Panel III criteria in nonobese nondiabetic subjects.

\section{Diabetes Care. 2008;31(3):562-568. doi:10.2337/dc07-1526}

17. Pacifico L, Cantisani V, Ricci P, Osborn JF, Schiavo E, Anania C, et al. Nonalcoholic fatty liver disease and carotid atherosclerosis in children. Pediatr Res. 2008;63(4):423427. doi:10.1203/PDR.0b013e318165b8e7.

18. Chalmers J, Ban L, Leena KB, Edwards K L, Grove JL, Aithal G P, Shenoy K T et al Cohort profile: the Trivandrum non-alcoholic fatty liver disease (NAFLD) cohort. BMJ Open 2019;9:e027244. doi: 10.1136/bmjopen-2018-027244.

19. Romeo S, Kozlitina J, Xing C, Pertsemlidis A, Cox D, Pennacchio LA, et al. Genetic variation in PNPLA3 confers susceptibility to nonalcoholic fatty liver disease. Nat Genet. 2008;40(12):1461-1465. doi:10.1038/ng.257.

20. Valenti L, Al-Serri A, Daly AK, Galmozzi E, Rametta R, Dongiovanni P, et al Homozygosity for the patatin-like phospholipase-3/adiponutrin I148M polymorphism influences liver fibrosis in patients with nonalcoholic fatty liver disease. Hepatology. 2010 Apr;51: 1209-17.

21. Hui Y, Yu-Yuan L, Yu-Qiang N, Wei-Hong S, Yan-Lei D, Xiao-Bo L, et al. Effect of peroxisome proliferator-activated receptors-gamma and co-activator-1alpha genetic polymorphisms on plasma adiponectin levels and susceptibility of non-alcoholic fatty polymorphisms on plasma adiponectin levels and susceptibility of non-alcoholic fatty Feb;28(2):288]. Liver Int. 2008;28(3):385-392. doi:10.1111/j.1478-3231.2007.01623.x

22. Petersen KF, Dufour S, Hariri A, Nelson-Williams C, Foo JN, Zhang XM, et al Apolipoprotein C3 gene variants in nonalcoholic fatty liver disease. N Engl J Med. 2010;362(12):1082-1089. doi:10.1056/NEJMoa0907295

23. Wu CW, Chu ES, Lam CN, et al. PPARgamma is essential for protection agains nonalcoholic steatohepatitis. Gene Ther. 2010;17(6):790-798. doi:10.1038/gt.2010.41

24. Tian C, Stokowski RP, Kershenobich D, Ballinger DG, Hinds DA. Variant in PNPLA3 is associated with alcoholic liver disease. Nat Genet. 2010;42 (1):21-23. doi:10.1038/ng. 488

25. Karpe F, Lundahl B, Ehrenborg E, Eriksson P, Hamsten A. A common functional polymorphism in the promoter region of the microsomal triglyceride transfer protein gene influences plasma LDL levels. Arterioscler Thromb Vasc Biol. 1998;18(5):756761. doi:10.1161/01.atv.18.5.756

26. Ledmyr H, Karpe F, Lundahl B, McKinnon M, Skoglund-Andersson C, Ehrenborg E. Variants of the microsomal triglyceride transfer protein gene are associated with plasm cholesterol levels and body mass index. J Lipid Res. 2002;43(1):51-58

27. Couture P, Otvos JD, Cupples LA, Wilson PW, Schaefer EJ, Ordovas JM. Absence o association between genetic variation in the promoter of the microsomal triglyceride transfer protein gene and plasma lipoproteins in the Framingham Offspring Study Atherosclerosis. 2000;148(2):337-343. doi:10.1016/s0021-9150(99)00281-6

28. Juo SH, Han Z, Smith JD, Colangelo L, Liu K. Common polymorphism in promoter of microsomal triglyceride transfer protein gene influences cholesterol, ApoB, and triglyceride levels in young african american men: results from the coronary artery risk development in young adults (CARDIA) study. Arterioscler Thromb Vasc Biol. 2000;20(5):1316-1322. doi:10.1161/01.atv.20.5.1316

29. Mirandola S, Osterreicher CH, Marcolongo M, Datz C, Aigner E, Schlabrakowski A, e al. Microsomal triglyceride transfer protein polymorphism $(-493 \mathrm{G} / \mathrm{T})$ is associated with hepatic steatosis in patients with chronic hepatitis C. Liver Int. 2009;29(4):557-565. doi:10.1111/j.1478-3231.2008.01892.x

30. Zampino R, Ingrosso D, Durante-Mangoni E, Capasso R, Tripodi MF, Restivo L, et al Microsomal triglyceride transfer protein (MTP) $-493 \mathrm{G} / \mathrm{T}$ gene polymorphism contributes to fat liver accumulation in HCV genotype 3 infected patients. J Viral Hepat. 2008;15(10):740-746. doi:10.1111/j.1365-2893.2008.00994.x

31. Shenoy KT, Lena KB, Sali N, Syam S, Shenoy ST, Rajadhyaksha VD, et al. Rationale and design for the CARDIOVIT Study (Cardiovit, Atherosclerotic vascular disease and hypeRhomocysteinemia: an epiDemiological study in Indians, additionally evaluating the effect of Oral VITamin supplementation). Curr Med Res Opin. 2006 Apr;22: 641-8. DOI: $10.1185 / 030079906$ X96344

32. Jha P, Jacob B, Gajalakshmi V, et al. A nationally representative case-control study of smoking and death in India. N Engl J Med. 2008;358(11):1137-1147. doi:10.1056/ NEJMsa0707719

33. Saadeh S, Younossi ZM, Remer EM, Gramlich T, Ong JP, Hurley M, et al. The utility of radiological imaging in nonalcoholic fatty liver disease. Gastroenterology. 2002;123(3):745-750. doi:10.1053/gast.2002.35354

34. Alberti KG, Zimmet P, Shaw J; IDF Epidemiology Task Force Consensus Group. The metabolic syndrome--a new worldwide definition. Lancet. 2005;366(9491):1059-1062. doi: 10.1016/S0140-6736(05)67402-8

35. Bedogni G, Miglioli L, Masutti F, Tiribelli C, Marchesini G, Bellentani S. Prevalence of and risk factors for nonalcoholic fatty liver disease: the Dionysos nutrition and live study. Hepatology. 2005;42(1):44-52. doi:10.1002/hep.20734

35. Parés A, Tresserras R, Núñez I, et al. Prevalence and factors associated to the presence of fatty liver in apparently healthy adult men. Med Clin (Barc). 2000;114(15):561-565. doi: $10.1016 / \mathrm{s} 0025-7753(00) 71364-9$

37. Weston SR, Leyden W, Murphy R, Bass NM, Bell BP, Manos MM, et al. Racial and ethnic distribution of nonalcoholic fatty liver in persons with newly diagnosed chronic liver disease. Hepatology. 2005;41(2):372-379. doi:10.1002/hep.20554

38. Dassanayake AS, Kasturiratne A, Rajindrajith S, Kalubowila U, Chakrawarthi S, De Silva AP, et al. Prevalence and risk factors for non-alcoholic fatty liver disease among adults in an urban Sri Lankan population. J Gastroenterol Hepatol. 2009;24(7):12841288. doi:10.1111/j.1440-1746.2009.05831.x

39. Hultcrantz R, Gabrielsson N. Patients with persistent elevation of aminotransferases: investigation with ultrasonography, radionuclide imaging and liver biopsy. J Intern Med. 1993;233(1):7-12. doi:10.1111/j.1365-2796.1993.tb00640.x

40. Shimizu I, Kohno N, Tamaki K, Shono M, Huang HW, He JH, Yao DF. Female hepatology: favorable role of estrogen in chronic liver disease with hepatitis B virus infection. World J Gastroenterol. 2007 Aug 28;13(32):4295-305. doi 10.3748/wjg.v13.i32.4295. PMID: 17708600; PMCID: PMC4250853.

41. Hagymási, Krisztina, et al. "[Role of the Endocrine System in the Pathogenesis of Nonalcoholic Fatty Liver Disease]." Orvosi Hetilap, vol. 150, no. 48, 2009, pp. 2173-81.

42. Banerjee A, Rose R, Johnson GA, Burghardt RC, Ramaiah SK. The Influence of Estrogen on Hepatobiliary Osteopontin (SPP1) Expression in a Female Rodent Model of Alcoholic Steatohepatitis. Toxicologic Pathology. 2009;37(4):492-501. doi:10.1177 0192623309335633 .

43. Gutierrez-Grobe Y, Ponciano-Rodríguez G, Ramos MH, Uribe M, Méndez-Sánchez N Prevalence of non alcoholic fatty liver disease in premenopausal, posmenopausal and polycystic ovary syndrome women. The role of estrogens. Ann Hepatol. 2010;9(4):402-409. 